\title{
Research on sexuality and religion: Some reflections on accomplishments and future directions
}

\author{
Andrew Kam-Tuck Yip \\ University of Nottingham, $U K$
}

Sexualities has always occupied a special place in my heart, for two reasons. First, I closely identify the journal with its founding editor, Professor Ken Plummer, who examined my $\mathrm{PhD}$ thesis - on gay male Christian partnerships - about three years prior to the birth of this journal. The viva experience was highly positive and affirmative, thanks to Ken's inspiring ability to lift my timorous spirit while rigorously examining all aspects of the research. I then vowed that, when my turn came to examine a $\mathrm{PhD}$ thesis, I would adopt his approach. Twenty odd years down the road, I still remind myself to 'do a Plummer' before I step into a viva. The other reason I am emotionally close to this journal is that its birth almost coincided with the commencement of my own post- $\mathrm{PhD}$ career. I remember feeling rather excited while reading the first issue of the journal, being confident that it would make a significant contribution to the study of sexualities. I wanted very much to be a part of this exciting development. But I had to wait until 2003 before my article appeared in it for the first time. Since then, I have had the opportunity to guest-edit a special issue in 2010 on sexuality and religion, and publish another article in 2018. Having served as an occasional reviewer over the years, and an associate editorial board member since 2013, I accepted with no hesitation when the invitation to become a full editorial board member came in 2016.

There is no denying that, over the past twenty years, Sexualities has been a fecund land for the germination of critical research on sexuality: sexuality as discursive and contested practices, deeply embedded in socio-cultural, political, and historical contexts, rather than 
simply a set of bodily performances and acts amenable to only positivistic examinations. Within this framework, it has also provided a much-needed intellectual - and political platform for the growth of literature on non-normative sexualities. Indeed, it opens the door to high-quality and critical articles on sexualities that might have found it difficult to locate a home elsewhere. Scholars like myself who started their academic journeys in the mid-1990s have surely benefitted much from this opportunity that Sexualities offers, not only to publish, but also to participate in critical debate and learning.

Owing to the fact that my primary research area lies in the field of religion and sexuality, over the years, I have been paying particular attention to the articles in this area published in this journal, whether as a reader or a reviewer. This experience has offered me a much-valued perspective on not only the development of research on sexuality and religion as represented by this journal, but also on scholarly research in this area more broadly. When Ken examined my $\mathrm{PhD}$ thesis in 1995 , he reassured me that the intersection of sexuality and religion was so acutely under-researched that I should channel energy into developing this research avenue. I must have taken his advice rather seriously, because I have stayed with this field until now, strenuously bringing more layers and dimensions into this research endeavour as I go and learn.

Professionally, the early 1990s was a lonely time for me. The scarce corpus of literature on sexuality and religion - more specifically, on homosexuality and Christianity - was primarily theological in nature. Nonetheless, in spite of the absence of a sociological lens in this body of literature, what was available was ground-breaking and inspiring. It de-stabilised the heteronormative foundation of systematic theology generally, and exposed the exclusivist and exclusionary core of its top-down theology of sexuality. Encounters with this body of literature fired up my sociological imagination and fuelled the desire to examine specifically how lives were lived, for people who had to navigate their ways through the vortex of the 
controversy of non-normative sexualities in religion. The emergence of Sexualities, with its openness to detailed studies of non-normative sexualities, gave me hope that this area of study was a worthwhile avenue to pursue.

In the past twenty years or so, the sociological study of sexuality and religion has come a long way indeed. The professional loneliness I experienced in 1990s was incrementally replaced by a sense of excitement, as research on non-normative sexualities and religion proliferated (for more details, see e.g. Hunt, 2015). In addition, Hunt's (2012) five-volume collection also offers an impressive range of previously-published works on and sexuality and religion more broadly. Suffice it to say that this body of literature has collectively mounted a credible challenge to the powerful secularist bias in academic and popular discourses of sexuality and religion. In this biased view, religious spaces, cultures, and structures (as opposed to secular ones) are inherently conservative and restrictive on sexuality issues; thus religious actors (as also sexed beings) are consequently 'agentically-constrained'. Empirical research has consistently demonstrated that, whilst stories of tension and conflict continue to persist, there are also the less-frequently reported narratives of integration, transformation, and growth. This is especially evident amongst young religious actors who, compared to the older generations, are more pragmatic and pluralist in their construction of religious identities, emphasising the functionality and usefulness of religious beliefs rather than dogma and tradition. When it comes to sexuality matters, they also demonstrate the 'individualisation of sexual ethics' - as part and parcel of their broader endeavour to construct 'ethics for life' which involves reflexive adaptation of religious dogma and beliefs, rather than uncritical and complete adoption or rejection of them (e.g. Collins-Mayo and Dandelion, 2010; Page and Yip, 2017; Yip and Page, 2013).

The growth of research on sexuality and religion in the past two to three decades has led to some scholars asserting that the field has reached a saturated point. I disagree. What 
really excites me about research on the intersection of sexuality and religion is the gradual pushing of boundaries. As far as the religious dimension of this intersection is concerned, whilst Christianity continues to dominate, the research agenda has moved beyond the usual Global North context, telling stories from, for instance, Africa and Asia. Furthermore, the research agenda has also begun to open up to other religions, especially Islam and Judaism (e.g. Chan and Huang, 2014; Chitando and van Klinken, 2016; Shah, 2018). Besides, the conventional focus on institutional settings and traditional religious authority structures, whilst still relevant, is gradually giving way to the exploration of non-institutional spiritual spaces and practices. This is a much-welcome development, because it de-centralises Christianity and mainstreams other religions, which will contribute to a more nuanced understanding of the roles and functions of religions in our increasingly diverse and complex society. The exploration of non-institutional spiritual spaces and practices also sensitises scholars to the lived dimension of religion: religion as practice; religion as lived experiences, with all their complexities and messiness. Another inspiring development related to this is the emergence of sociological study of nonreligion and unbelief (e.g. Lee, 2005). Hitherto cast as the 'Other' of religion, nonreligion and unbelief have traditionally received little scholarly attention in their own right. But that is changing. Recent years have witnessed the emergence of detailed scholarly research on them as a 'belief system' that is meaning-generating and influential of individuals' worldview and social positioning including, of course, the management of their sexuality.

On the sexuality side of the intersection between sexuality and religion, exploration of non-normative sexualities which conventionally privileges gay, and to a lesser extent, lesbian sexuality, is slowly but surely opening up to the hitherto under-represented topics of bisexuality - and transgenderism, if we broaden the scope to include gender. All these developments enrich the interactional study of sexuality and religion enormously, generating new insights that 
expand current understandings and debates (e.g. Mollenkott, 2007; Toft, 2014). There is much more to be done yet, especially if we are committed to adopting a global and cosmopolitan perspective on sexualities (e.g. Plummer, 2015), and indeed, religion (e.g. Shipley, 2014; Smith, Munt and Yip, 2016). The intersectional politics of sexuality and religion on the global stage increasingly involves transnational multi-layered networks of actors and players. The outcomes of such politics are diverse and the implications more far-reaching. We must continue to keep a firm gaze on these often explosive intersections.

Methodologically, I know I am in a minority in this respect, but I would really love to see more willingness in the employment of qualitative and quantitative methodologies in the study of sexuality and religion. They have relative strengths and limitations. Therefore, their complementarity is of great value. I genuinely believe that, if the currently dominant qualitative paradigm in the sociological study of sexuality and religion is willing to incorporate more quantitative methodologies, it would be a positive step forward indeed.

Undoubtedly, Sexualities has been a much-valued travel companion in my academic journey. I am grateful for the various horizon-expanding opportunities it has offered me. I am therefore very pleased to be a part of this celebration issue, and look forward to the continuation of this meaningful journey. Happy $20^{\text {th }}$ anniversary!

\section{References}

Chan S and Huang P (2014) Religion and homosexuality in contemporary China: Debates, identity, and voices. In: Shipley, H (ed) Globalized Religion and Sexual Identity: Contexts, Contestations, Voices. Leiden: Brill, pp. 170-192.

Chitando E and van Klinken A (2016) Christianity and Controversies over Homosexuality in Contemporary Africa. London: Routledge.

Collins-Mayo S and Dandelion P (2010) Religion and Youth. Aldershot: Ashgate. 
Hunt S (2010) The Library of Essays on Sexuality and Religion (5 volumes). Farnham: Ashgate.

Hunt S (2015) Religion and LGBTQ Sexualities: Critical Essays. Farnham: Ashgate.

Lee L (2015) Recognising the Non-religious: Reimagining the Secular. Oxford: Oxford University Press.

Mollenkott VR (2007) Omnigender: A Trans-religious Approach. Cleveland; Pilgrim Press.

Page S and Yip AKT (2017) Understanding Young Buddhists: Living out Ethical Journeys. Leiden: Brill.

Plummer K (2015) Cosmopolitan Sexualities: Hope and the Humanist Imagination. Cambridge: Polity Press.

Shah S (2018) The Making of a Gay Muslim: Religion, Sexuality and Identity in Malaysia and Britain. Basingstoke: Palgrave Macmillan.

Shipley H (2014) Globalized Religion and Sexual Identity Contexts, Contestations, Voices. Leiden: Brill.

Smith S, Munt SR and Yip AKT (2016) Cosmopolitan Dharma: Race, Sexuality, and Gender in British Buddhism. Leiden: Brill.

Toft A (2014) Re-imagining bisexuality and Christianity: The negotiation of Christianity in the lives of bisexual women and men. Sexualities 17(5/6): 546-564.

Yip, AKT and Page S (2013) Religion and Sexual Identities: A Multi-faith Exploration of Young Adults. Farnham: Ashgate.

\section{Biographical note:}

Andrew Kam-Tuck is Professor of Sociology at University of Nottingham, UK. His recent books include: Critical Pedagogy, Sexuality Education and Young People (2018, with Fida Sanjakdar), Understanding Young Buddhists: Living out Ethical Journeys (2017, with Sarah- 
Jane Page), Cosmopolitan Dharma: Race, Sexuality, and Gender in British Buddhism (2016, with Sharon Smith and Sally R. Munt), and Religious and Sexual Identities: A Multi-faith Exploration of Young Adults (2013, with Sarah-Jane Page). 